\title{
La Tirana. Culto Mariano en el Desierto de Atacama del Norte Grande de Chile
}

\section{La Tirana. Marian Cult in the Atacama Desert of the Large Northern Zone of Chile}

\author{
Bernardo Guerrero \\ Bernardo.guerrero@unap.cl@0000-0002-8847-7721 \\ Universidad Arturo Prat, Chile. Obispo Labbé 1235. Iquique, Chile. C.P. 11011237.
}

\section{INFO ARTÍCULO}

Recibido: 03-10-2020

Revisado: 22-01-2021

Aceptado: 22-01-2021

\section{PALABRAS CLAVE}

Desierto de Atacama

Culto mariano

Norte Grande

La Tirana

\section{KEYWORDS}

Atacama desert

Marian cult

Large Northern Zone

La Tirana

\begin{abstract}
RESUMEN
En este trabajo reflexionamos sobre las relaciones que se establecen entre la religiosidad popular y el desierto de Atacama en el Norte Grande de Chile. Para ello vemos como ese inmenso territorio que es el desierto es percibido por las elites políticas, militares y eclesiales. Primero como un lugar carente de vida y segundo como fuentes de riquezas sobre todo minerales. La fiesta de La Tirana y su vasto peregrinaje ha provocado la sacralización de algunas de sus partes. Lo que era un no-lugar se transformó en un lugar lleno de sentido. La religiosidad popular es como veremos más adelante una inscripción territorial. En términos metodológicos hemos realizado desde hace más de una década de viajes prolongados a esta fiesta, una observación e interpretación desde el punto de vista de los peregrinos. Largas conversaciones, análisis del cancionero religioso, entre otros, constituyen nuestras fuentes empíricas. Concluimos que gracias al peregrinaje el desierto de ser concebido, como algo vacío, se llena de vida.
\end{abstract}

\begin{abstract}
In this work we reflect on the relationships established between popular religiosity and the Atacama Desert in the Norte Grande of Chile. For this we see how that immense territory that is the desert is perceived by the political, military and ecclesial elites. First as a place lacking of life and second as sources of wealth, especially minerals. The festival of La Tirana and its vast pilgrimage has caused the sacralization of some of its parts. What was a non-place was transformed into a place full of meaning. Popular religiosity is, as we shall see later, a territorial inscription. In methodological terms, we have made long trips to this festival for more than a decade, an observation and interpretation from the pilgrims' point of view. Long conversations, analysis of the religious songbook, among others, constitute our empirical sources. We conclude that thanks to the pilgrimage the desert of being conceived as something empty, is filled with life.
\end{abstract}


"Pampa desierto nortino, ha florecido un rosal" De la canción La Reina del Tamarugal Veas y Miranda

\section{INTRODUCCIÓN}

La cita con la que comienza este trabajo corresponde a un verso de la canción "Reina del Tamarugal" ganadora del concurso folklórico del festival de Viña del Mar, el año 1985, en Chile. En otro trabajo hemos analizado esa y otras canciones que dan cuenta de esta festividad (Guerrero, 2017). El elemento que sobresale en esta canción es la idea de que el desierto puede devenir, gracias a la peregrinación mariana, en jardín. Se trata, por cierto, de una metáfora.

Cada 16 de julio cerca de doscientas mil personas se reúnen en el pequeño pueblo de La Tirana, ubicado a 74 kms de Iquique, en el Norte Grande de Chile, a venerar a la virgen del Carmen. Es una fiesta a la que acuden cerca de 220 bailes o cofradías religiosas que danzan y cantan a la virgen. Una fiesta colorida en la que cada uno de estos grupos asumen la representación de un otro: Chunchos, Cuyacas, Morenos, los más antiguos de la fiesta. Luego Gitanos e indios pieles rojas, diabladas, sambos, morenadas, tinkus, de influencia boliviana. Grupos mixtos o bien exclusivamente de hombres (chinos y algunos Morenos) o de mujeres (Las Cuyacas). Se hacen acompañar de bandas de músicos, que tocan percusión e instrumentos de bronces. Es una fiesta que se masifica desde fines del siglo XIX, por la actividad salitrera. Recordar que producto de la guerra del Pacífico o del Salitre (1879-1893), Chile conquista las provincias de Antofagasta y Tarapacá, rica en yacimientos salitreros. La base social de esta manifiestación estaba compuesta por el proletariado que trabajaba en la extracción del salitre y que dio paso en los primeros años del siglo XX a la formación del movimiento obrero uno de los más antiguos de América Larina. Muchos de estos, hombres y mujeres fueron masacrados en Iquique en la huelga del 21 de diciembre de 1907. ${ }^{1}$ Una encuesta realizada el año 1970 a una muestra de estos danzantes manifestó que cerca del 70\% había votado por el candidato marxista Salvador Allende (Van Kessel, 1987). Muchos de estos bailarines y dirigentes fueron detenidos luego del golpe de Estado de 1973. Las relaciones entre estos grupos de danzantes con la iglesia católica no han estado exentas de conflictos. La lucha por el control de la fiesta es el punto central (Tennekes \& Koster, 1986).

La leyenda que da origen a esta fiesta habla de la resistencia indígena a la presencia española. Una princesa india Ñusta Huillac, apodada como La Tirana, por su crueldad, toma prisionero a un grupo de conquistadores, entre ellos a un portugués de nombre Vasco de Almeyda. En prisión ambos se enamoran y la princesa se convierte al cristianismo. Descubiertos huyen, pero son alcanzados por la feleches y mueren. En el siglo XVI un fraile de apellido Rondón, descubre la tumba. Y ahí se inicia la peregrinación. Esta leyenda fue ampliamente divulgada por el historiador peruano Cuneo Vidal. En todo caso, hay que considerar este relato como una pieza literaria más, que como un hecho histórico (Núñez, 2015).

El pueblo de La Tirana está ubicado en la depresión intermedia, en el desierto de Atacama, el más árido del mundo, a una altura de 800 metros sobre el nivel del mar Pertenece a la comuna de Pozo Almonte y la distancia con Iquique, el centro más poblado es de 74 kilómetros. ¿Puede florecer un rosal en el desierto? La respuesta clásica es no. Sin embargo, hombres y mujeres del desierto más seco del mundo, han contrariado esa máxima y han construido un inmenso jardín. Ese jardín inmenso, colorido y sonoro se llama religiosidad popular mariana.

Estas reflexiones que ofrezco a continuación pretenden vincular la idea de desierto a religión y como esta última, construye en ese lugar donde no hay nada, un no-lugar, en un territorio de una densidad simbólica, humano y divino a la vez.

1. Esta matanza fue conocida a nivel internacional por la obra de Luis Advis e interpretada por el conjunto Quilapayún: Canta Popular Santa María de Iquique, grabada el año 1970. 


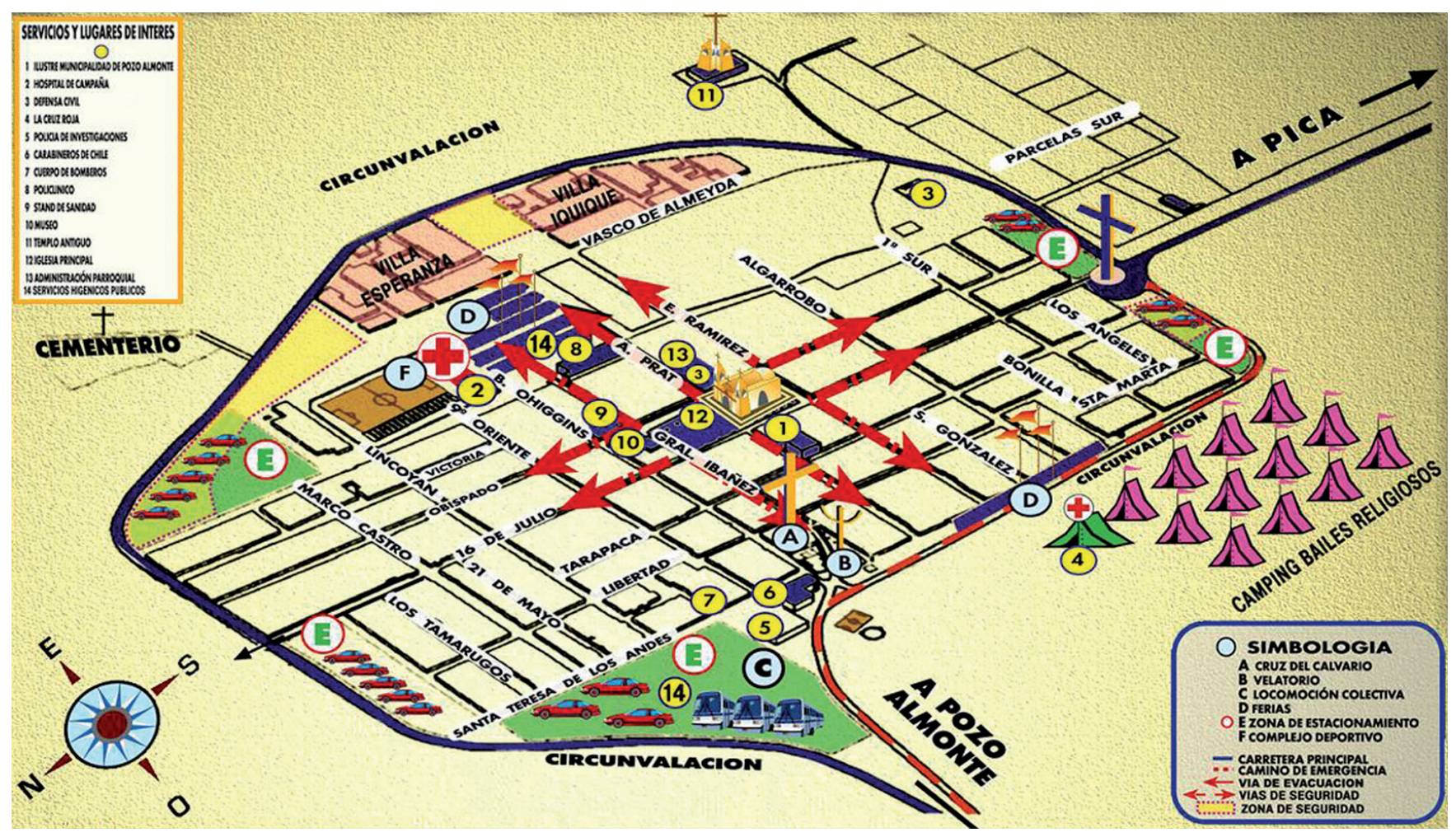

Figura 1. Plano del poblado de La Tirana, en tiempo de la fiesta. Año 2019. Fuente: Ilustre Municipalidad de Pozo Almonte.

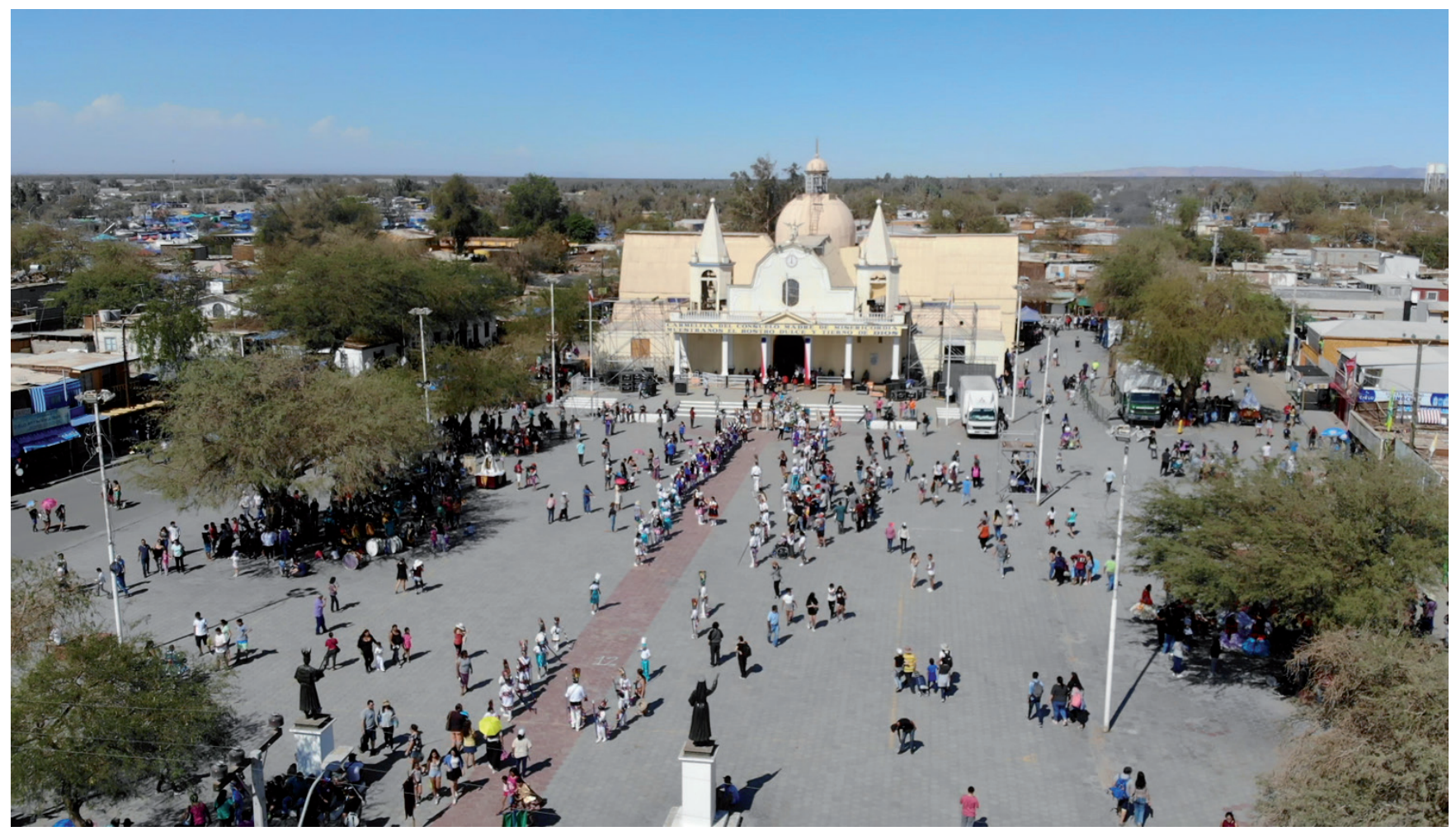

Figura 2. Explanada del pueblo de La Tirana, donde los bailes religiosos danzan a la virgen. Fuente: Rodrigo Orchard. Proyecto www.tarapacaenelmundo.com. Instituto Isluga. Universidad Arturo Prat, 2019. 


\section{MARCO TEÓRICO}

La bibliografía sobre las relaciones entre lugar y no lugar, se ha centrado en ver como un lugar se transforma en su antípoda, es decir, en un no lugar. Marc Auge, el autor, de esta interesante figura dicotómica, centra su análisis en la llamada sobre-modernidad que vive el actual capitalismo y como ésta, transforma por múltiples razones un lugar, por ejemplo, una plaza, en un supermercado, o en una estación de expendio de combustibles. Los ejemplos abundan. Augé en otra publicación (2014) aclara y profundiza esta noción. Plantea que el concepto de lugar surgía de su experiencia de terreno en África, en la que se advertían la existencia de relaciones sociales y de reglas de residencia. Agrega además que no existían no lugares en el sentido absoluto. Son ambas nociones relativas y la de no lugar, ambivalente. Plantea que un no lugar es el espacio absoluto de la libertad y como tal no existe. Siguiendo a Segato, la noción de territorio es representación. Agrega es "espacio representado y apropiado" (200, p. 71). Es apropiación política del espacio. Implica administración, delimitación, clasificación, uso, distribución, defensa, y muy especialmente identificación (Segato, 2007). En esa misma dirección Augé nos dice que el espacio no es más que la simbolización de la naturaleza. Y que además tiene memoria (2014). Los paisajes, agrega, son culturales. En este sentido, la fiesta de La Tirana, es memoria de un paisaje compartido. Bachelard (2012) habla de la topofilia como una forma de entender el apego a un lugar determinado. Lugares que pueden contener experiencias públicas y privadas. En este caso de La Tirana se mezclan ambas. El peregrino vive la fiesta tanto en forma individual como colectiva. Además, Chatterjee (2008) plantea que tanto el espacio como el tiempo no son homogéneos. Tienen densidades diferentes y otros son más bien neutros. Son los seres humanos lo que le otorgan y carga de sentido y significado.

En el caso que deseamos analizar invertimos el análisis para destacar como un no-lugar, en este caso el desierto de Atacama, mediante las prácticas de la religiosidad popular, se transforma no sólo en un lugar, sino que además en un lugar sagrado.

Partimos de la idea de que la religiosidad popular, expresada en la fiesta de La Tirana, en Tarapacá; Ayquina, en Antofagasta y Las Peñas en Arica, es una estrategia de inscripción territorial (Guerrero, 2018), que dota, por la aparición de la virgen o el hallazgo de la tumba, en este caso de la Ñusta Huillac que da origen a la fiesta de La Tirana, al territorio de una densidad religiosa a un no-lugar, definido como una zona en que "no habita nada". Cuando hablamos de inscripción territorial aludimos al hecho de que los peregrinos, en este caso, domestican parte de la geografía y la llenan de contenidos religiosos, ya sea como recordatorio de un algún evento importante o bien como lugar de encuentro, como es el caso de la fiesta de La Tirana, en el Norte Grande de Chile.

El paso de la "nada" al "todo", es obra de un peregrinaje masivo que, desde fines del siglo XIX, por mediación de la industria del salitre, hasta la actualidad muestra un gran vigor. Deseamos en este trabajo ver como ese territorio es nombrado y ocupado con categorías que denotan un gran arraigo, de un conjunto de relaciones sociales y de reglas de sociabilidad. El desierto a través de la mediación de la religiosidad popular, deviene en lugar sagrado, sitio de encuentro, territorio de milagros, de danzas, música, etc. Un lugar que se estructura en torno a los tiempos y espacios que el culto a la virgen del Carmen, impone. Un sitio donde el marianismo se reproduce año tras año.

Estos santuarios del Norte Grande realzan en sus festividades un ethos comunitario, en la que los bailes religiosos portan una tradición que no se puede entender sin su permanente reproducción. Se trata de una práctica basada, por cierto, en la tradición oral y con ejes de tiempo y espacio distinto a la de la modernidad importada desde Europa. El desierto es vacío si se le mira desde una posición eurocéntrica, colonial y centralista como es el caso de Chile. Desde aquí, desde el Norte Grande de Chile con sus fronteras civiles, es el lugar de la epifanía, de culto, del peregrinaje.

\section{METODOLOGÍA}

La fiesta de La Tirana, para efecto de nuestro análisis la entendemos como un complejo texto que hay que interpretar. Ese es un primer desafío metodológico, ya que implica entender su dinámica interna y sus relaciones 
con la sociedad que la circunda. Además, partimos del hecho que la fiesta, como todo fenómeno socio-cultural, va cambiando e integrando nuevos elementos que son resignificados, por ejemplo, adaptar una canción de moda, al ritmo de cada baile religioso.

En términos metodológicos hemos realizado desde hace más de una década viajes prolongados a esta fiesta, en el marco de varios proyectos de investigación. Ello nos ha servido para crear relaciones de amistad con los peregrinos, que se traducen en largas conversaciones sobre la historia de sus cofradías religiosas, sus proyectos y problemas para mantener esas estructuras y de la importancia que tiene para ellos, el asistir a la fiesta, cuestión que este año no se pudo realizar por el Covid 19. Aun si lograron a través de las redes sociales reactualizar sus creencias. Informantes estratégicos, tanto hombres como mujeres, con funciones rituales, como el caporal y socios y socias que no danzan, pero que apoyan fuertemente estas actividades, nos ha sido de utilidad.

Hemos recogido y analizado sus libretas de cantos, entendiendo que estas piezas entregan información acerca de la relación que mantienen con la virgen y del sacrificio que deben hacer para asistir cada año. Hemos revisado videos documentales sobre la fiesta, el más antiguo, del año 1944, para tener imágenes de ese paisaje. Además, recogimos planos del pueblo en la que es posible ver en tiempos de fiesta como el pequeño pueblo crece.

Nos hemos movido entre esa delgada línea que existe entre la descripción y la interpretación, separando una de la otra. La primera tiene que ver con una mirada objetiva del territorio, por ejemplo, carente de vida y la segunda concibiéndolo como algo que hace posible la vida, la felicidad y el dolor. El peregrino que deja de bailar, ya sea por salud o por los años, experimenta un dolor no siempre fácil de describir.

En el trabajo de campo nos hemos dotado de dispositivos tecnológicos como cámaras de televisión, grabadoras y de máquinas fotográficas que nos han permitido registrar el paisaje y su dinámica en época de fiesta. Lo mismo que con las entrevistas filmadas que nos permiten, en su lectura, capturar quiebre en la voz, expresiones corporales, entre otras manifestaciones.

La experiencia de vivir la fiesta desde el punto de vista de los peregrinos, nos entrega un saber no siempre fácil de traducir al lenguaje científico: emociones, afectos, danza, humor entre otros aspectos que se consigue advertir a través de largas estadías con estos grupos de bailes.

\section{RESULTADOS}

\subsection{El desierto una experiencia extrema}

En el contexto de la nación chilena y de sus fronteras, el desierto, en tanto realidad y nomenclatura, paisaje y realidad despierta sentimientos de ambigüedad. Por un lado, se le reconoce como el escenario de la guerra del Pacífico (1879-1893) en la que Chile conquistó las ricas provincias de Tarapacá y Antofagasta, y, por otro lado, genera la sensación de miedo por lo desconocido, lo agreste y porque "ahí no hay nada". En palabras del poeta anarquista Francisco Pezoa, el lugar donde "nunca la flor creció" (Bravo \& Guerrero, 2000).

El desierto siempre fue un lugar de paso. Diego de Almagro y sus huestes supieron de él, cuando pasaron de Copiapó para llegar al Cusco. Advis en su libro El Desierto Conmovido (2008), describe esa marcha épica a lomo de caballo y a pie.

Hoy los fatigaba el frío é los proveía de temblores, mañana los asaba el calor, porque á las sierras se subcedian arenales é á los arenales pedregales espesos, y todo el camino falto de leña, é la que se halla son unas ramas ó matas que en llamas se van ó consumen. Es tan llena de maldición aquella tierra, que ciento y veinte leguas de este yermo que andovieron, no se vio sitio ni aparejo para poblar una choza (Oviedo, 1936, p. 70, citado por Advis, 2008, p. 131).

Los relatos de la guerra del Pacífico son ricos en descripción de un paisaje que los militares venidos del centro y del sur, jamás imaginaron, tal y como se muestra en Parvex (2017) "Apenas divisé la costa antofagastina me llamó la atención la resequedad de los cerros, la total ausencia de praderas y bosquecillos y la rugosidad de toda la seca geografía" (p. 39). Este otro testimonio de un soldado narra las aflicciones de una parte del cuerpo: 


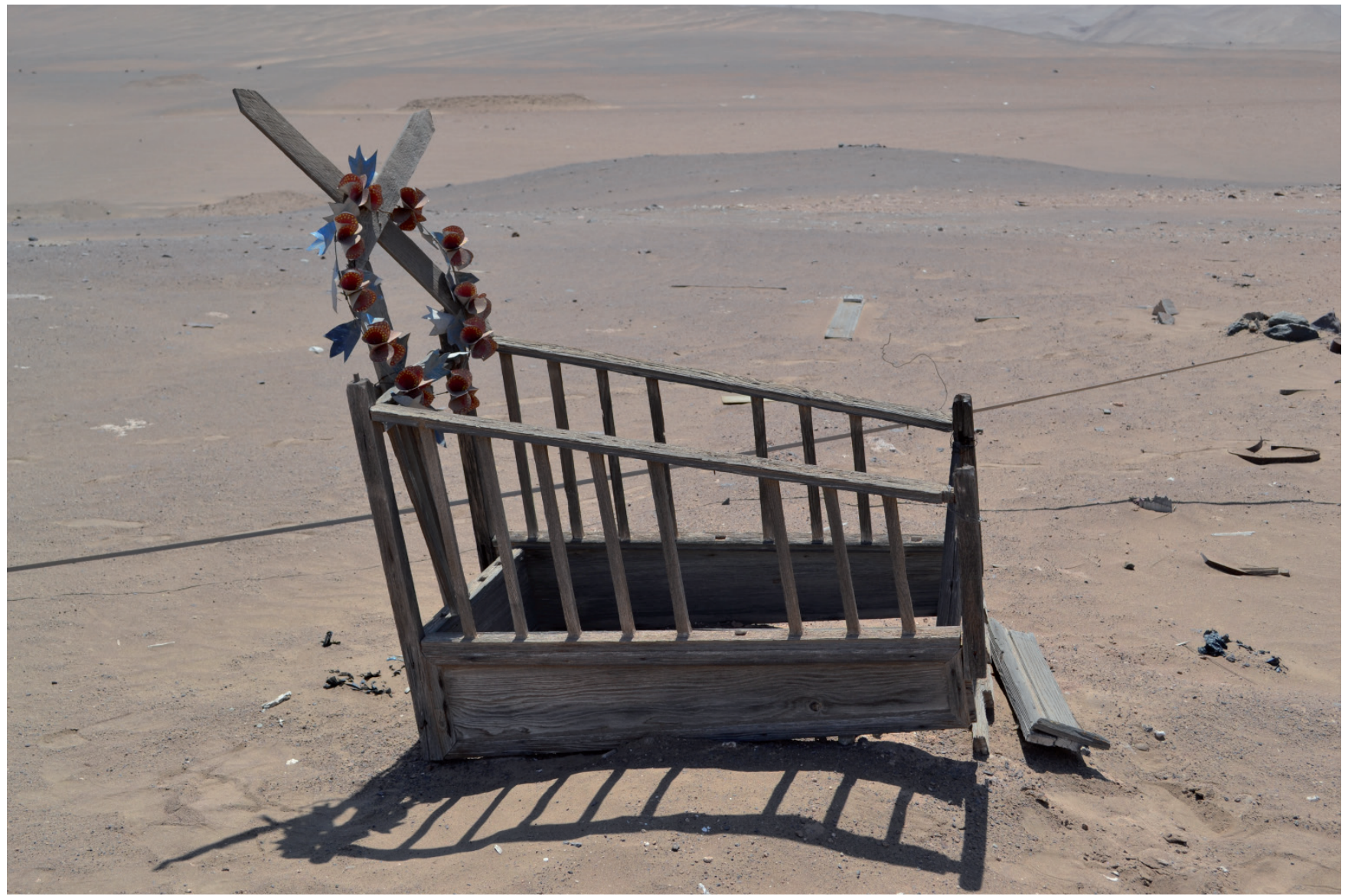

Figura 3. Tumba en un cementerio abandonado en el desierto de Atacama. Fuente: Rodrigo Orchard. Proyecto www. tarapacaenelmundo.com. Instituto Isluga. Universidad Arturo Prat, 2017.

Yo no puedo andar más de los pies todos empollados. Los llevaba con medias envueltos en pañuelos, pero nada me favorecía y sin poder echar a pies pelados por la causa de calor que estaba en la arena como re (h) coldo, ya me boté a la larga como muerto, aunque mala comparación, lo mismo que un bruto cargado, y el sol que me quemaba vivo (Gutiérrez, 1956, p. 30).

El desierto es percibido por gran parte de la población nacional, como un territorio vacío, carente de belleza. En palabras de Auge, un no-lugar (2000). A lo anterior se le suma su implacable clima, la ausencia de vegetación y sobre todo la carencia de vida humana. Este relato de un oficial de la guerra del Pacífico lo deja en evidencia:

Esos factores deben haber contribuido para que la larga marcha se hiciera muy llevadera y placentera, no obstante, los rigores del frío en las horas de oscuridad y la sequedad de ambiente y el sol aterrador durante el día" (Parvex, 2017, p. 44). Lo mismo sucede si tomamos en consideración lo expresado por Gutiérrez: "Ai harto padecimos con los calores en los ejercicios, que los sacaban aun desplayo arenoso, salitre, atormentados de polvos, de sudor y de sé, hasta que llegábamos al cuartel a descansar (1956, p. 24).

En un relato más contemporáneo, Jesús Bayo, a su llegada a Tocopilla desde Antofagasta, así lo describe:

Me evado en un mundo que dejé poblado de gentes y de voz, sueño con el bullicio y ruido de las grandes ciudades. Pero no, estoy en el desierto; la pampa con su litoral, y sus cerros están poblados de silencio y de soledad. Los hombres pueden adaptarse a estos parajes si logran ser inmortales o si convierten en fantasmas o en demonios, si llegan a ser santos o héroes (Bayo, 1995, p. 14). 
No obstante, lo anterior para el chileno del Norte Grande, el desierto no se puede entender sin su relación con los otros paisajes y nichos ecológicos que hacen de esta zona del país, una sola unidad. La costa, las quebradas y sus oasis y la cordillera, junto a la pampa o desierto, conforman una unidad que las primeras bandas de cazadores y recolectores supieran usar con eficiencia y cuidado del medio ambiente (Arriaza, 2015). Esta mirada de unidad de los diferentes pisos ecológicos es lo que John Murra (1975), denominó el control vertical de un máximo de pisos ecológicos. Lo anterior implicó una comunidad que supo administrar y utilizar estos recursos no sólo económicos, sino que también simbólicos. Gran parte del arte rupestre tarapaqueño está desplegado en el desierto.

\subsection{La religiosidad popular mariana y el desierto atacameño}

El culto mariano realizado en el pueblo de La Tirana, se ha convertido en la fiesta religiosa popular más grande de Chile. En el mes de julio crece la cantidad de turistas y de peregrinos que vienen de otros lugares del país. Hay cofradías religiosas que vienen de Santiago a bailarle a la virgen. Es, por tanto, una gran manifestación popular en que este pequeño pueblo se llena de comerciantes, camping para levantar carpas, etc.

Su base social, los peregrinos agrupados en los bailes religiosos fueron aumentando, ya sea por sus nuevos miembros o por su escolaridad. Si en los 70, según los estudios de Van Kessel (1987) eran en su mayoría población que no tenía más allá de la enseñanza básica completa, ahora hay profesionales egresados de las universidades y de los institutos profesionales.

A su vez los nuevos fenómenos de las migraciones de colombianos, ecuatorianos, dominicanos, más la migración histórica como de peruanos y bolivianos ha dinamizado estas manifestaciones populares. En la década de los años 80 en Iquique, por ejemplo, aparece el primer baile religioso, los Sambos Caporales, formado por bolivianos e iquiqueños y ubicados en un sector popular llamado ahora barrio boliviano, ex matadero. ${ }^{2}$

La situación de frontera del Norte Grande con relaciones históricas con países como Argentina, Bolivia y Perú, acrecienta los préstamos. La celebración en Iquique, por ejemplo, del Señor de los Milagros, organizada por la comunidad peruana la virgen de Urkupiña, organizada por los bolivianos así lo deja en evidencia. ${ }^{3}$

Al enfatizar el concepto de religiosidad popular como prácticas sociales totales enfatizamos su carácter dinámico y recurrente, pero expuesto a cambios e innovaciones. Son los actores organizados en los bailes religiosos los que generan prácticas culturales y religiosas que reproducen, pero a la vez recrean lo que les viene del pasado.

La religiosidad popular del Norte Grande de Chile, dialoga con el territorio en el que se asienta. A través de estas prácticas religiosas el desierto adquiere una dimensión humana y sobrenatural a la vez. Es el lugar del peregrinaje, de la devoción y del pago de los favores contraídos. La Tirana es el centro de peregrinaje más grande del norte de Chile, que recrea y reproduce estas prácticas.

Estos masivos peregrinajes están localizados geográficamente. A diferencia de otras expresiones de la religiosidad popular, como el pentecostalismo, por ejemplo, el territorio es una masa uniforme que no posee densidad religiosa. El pentecostalismo es la variante popular de protestantismo de gran crecimiento en América Latina, sus fieles pertenecen al mundo popular (Lalive, 1968). Para el pentecostalismo, el territorio es el lugar donde habita el demonio y sus aliados. Por lo mismo hay que hacer desaparecer todo vestigio de las fuerzas del mal. Una vez realizada esta operación de "limpieza", el lugar se convierte en habitable (Guerrero, 1994). Para estos grupos el espacio público es un territorio a conquistar. El templo, es el único lugar sagrado. Para la religiosidad popular mariana, el espacio público puede devenir en lugar sagrado. Un ejemplo es el culto a las animitas. Estas son personas que han muerto en forma trágica. En el lugar donde murieron se levanta un pequeño altar y a algunos de ellos se le atribuyen la realización de milagros (Plath, 2012).

2. Sobre su historia y actuales transformaciones: https://tarapacaenelmundo.com/barrio-boliviano/

3. Para más información revisar: https://www.tarapacaenelmundo.com/cineteca-tarapaquentildea 


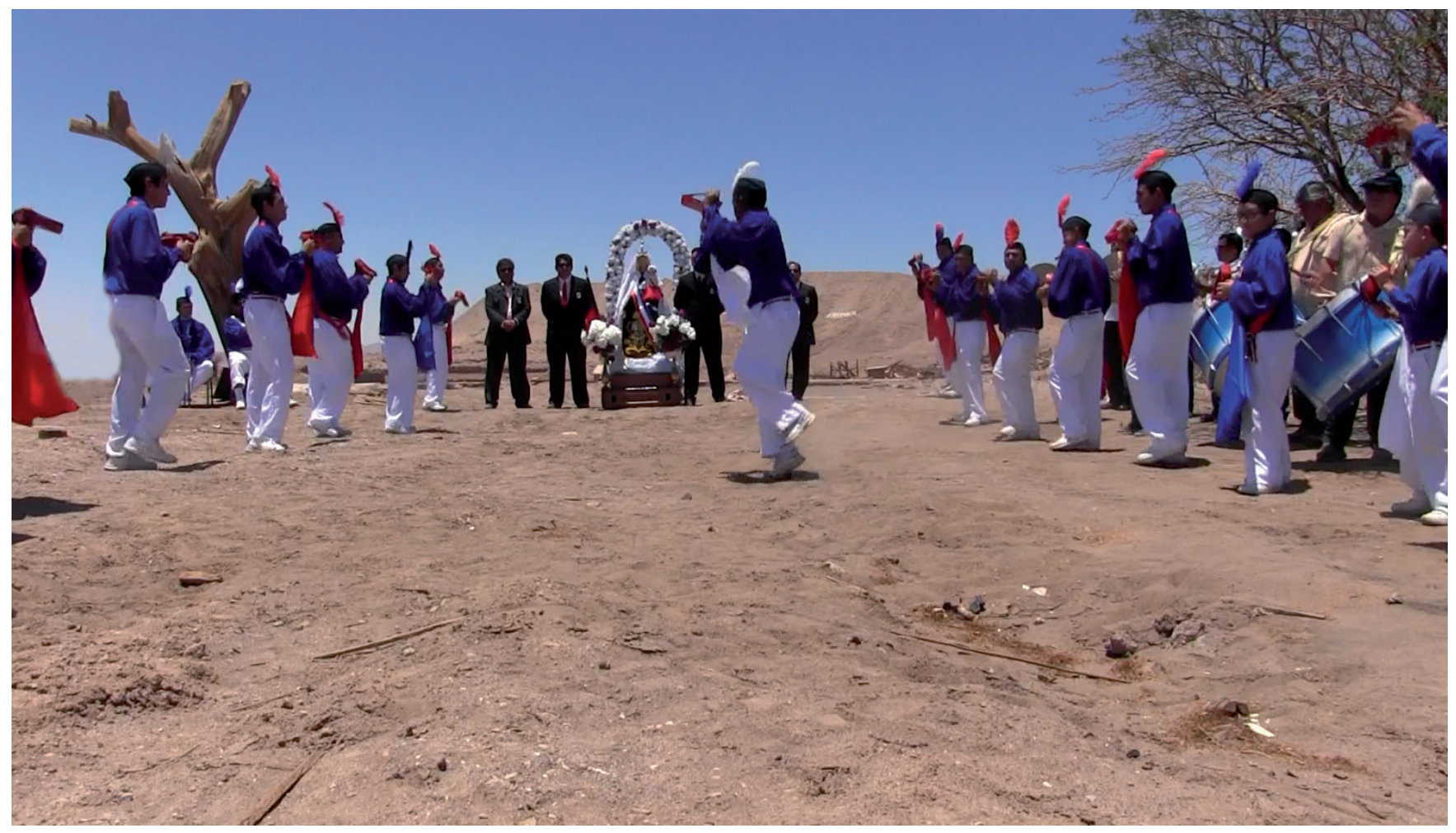

Figura 4. Mudanza del baile Moreno de Victoria, en la oficina salitrera del mismo nombre. Fuente: Rodrigo Orchard. Proyecto www.tarapacaenelmundo.com. Instituto Isluga. Universidad Arturo Prat, 2017.

Habitar el espacio en el Norte Grande de Chile, es de alguna manera, hacerse cargo de la historicidad del mismo y de sus dimensiones sagradas, como el caso de la virgen de La Tirana que realiza milagros al pueblo devoto.

La religiosidad popular del Norte Grande cuyos ejes son el peregrinaje y la fiesta, conversa permanentemente con el territorio. Los pueblos donde se realizan estas manifestaciones son, para los peregrinos, pueblos sagrados.

Concebimos la religiosidad popular según la interesante expresión de Eloísa Martín: “Así, propongo entender los gestos comprendidos bajo el concepto de religiosidad popular en términos de prácticas de sacralización: los diversos modos de hacer sagrado, de inscribir personas, lugares momentos, en esa textura diferencial del mundo-habitado" (2007, p. 77). Enfatiza aquí el componente de la praxis como forma de dotar a un territorio de una densidad religiosa.

Lo anterior, sin embargo, cobra sentido en la medida que entendamos a la religiosidad popular como una práctica social y culturalmente situada. En esta perspectiva tomamos la idea de Giddens, en tanto la relación entre acción y estructura, la podemos observar a través de la teoría de la estructuración. Escribe: "el dominio básico del estudio de las ciencias sociales, no es la experiencia de actor individual, ni la existencia de cualquier forma de totalidad social, sino las prácticas sociales ordenadas a través del tiempo y del espacio" $(1995$, p. 2). Esto es, que se desarrolla en un territorio históricamente configurado, sometido a devenires políticos, naturales y culturales. Independientemente de las fortalezas teóricas de las definiciones disponibles, conviene situar a estas en el territorio en que se desarrollan.

Podemos ver a la religiosidad popular mariana, además como un "espacio entre", según la expresión de Bhabha (2002). En el cruce entre la globalización y las culturas locales, se produce un espacio que permite la intersección, espacios entre-medio (in between) según la terminología de Bhabha (2002) que hace posible que actores sociales, los bailes religiosos, dotados de una capacidad de innovación, usen para sus fines rituales los bienes que el mercado pone a su disposición. "Estos espacios, entre-medio, proveen el terreno para elaborar estrategias de identidad, que inician nuevos signos de identidad y sitios innovadores de colaboración y cuestionamiento, en el acto mismo de definir la idea de sociedad" (2002, p. 18). 
De este modo con la noción de prácticas sociales, nos sirven para entender mejor el concepto de religiosidad popular, ayudado por cierto por la definición más arriba entregada de Martín. Y para evitar caer en los reduccionismos entre micro y macro, la noción de "entre medio" de Bhabha nos auxilia y nos deja ver las complejidades y riquezas de habitar en esos espacios.

Nuestra apuesta es ver las prácticas religiosas populares desde el territorio en que se asiente y ver como en ambas se produce una dialéctica que tiene como consecuencia una mutua transformación. Todo ello enmarcada por el uso que se hace del territorio, sus ocupaciones e inscripciones. El desierto vacío, ahora se llena por el peregrinaje.

\subsection{La religiosidad popular como inscripción territorial}

El territorio es el soporte sobre el cual los actores sociales producen la configuración socio-espacial de su vida cotidiana. En el caso de la fiesta de La Tirana, el descubrimiento de la cruz por el fraile Rondón, en el siglo XVI da origen a su leyenda. En el año 1944 se graba el primer documental sobre la fiesta de La Tirana, dirigido por Pablo Garrido. Una voz en off dice:

En la soledad de este desierto que calcina el sol del norte, vive todavía una leyenda de siglos. Leyenda que tuvo su origen cuando una bella princesa indígena se refugió con sus guerreros en los bosques del tamarugal convertidos hoy en un caserío solitario, y la hermosa Nusta Huillac, que resistió la dominación extranjera, cayó herida por el amor de su prisionera español Vasco de Almeida, quien la convirtió a su religión cristiana. Sin embargo, ambos murieron acribillados a flechazos. En el lugar de su muerte, se levantó más tarde la Iglesia de la Virgen del Carmen de La Tirana ${ }^{4}$.

El desierto adquiere entonces, gracias a ese hallazgo una significación diferente. Se le sacraliza y de ser nada según, la definición clásica (Vicuña, 1995) se transforma en un lugar lleno de vida y de esperanzas. El desierto es visto ahora como un lugar donde los milagros pueden acontecer. Todo esto coincide a la vez, con el descubrimiento de este espacio como fuente de riquezas, en este caso del salitre. El culto a la virgen del Carmen, resignifica el territorio y lo llena de sentido.

En este sentido la religiosidad popular es una práctica de sacralización, tal como se señaló más arriba. El culto a las animitas, es un ejemplo de ello, que además se manifiesta en el espacio público. Cientos de pequeños altares con sus cruces y fotografías, fotos del difunto o difunta y a veces el emblema de su club deportivo, evidencian la íntima conexión entre los vivos y los muertos. Las animitas sacralizan el territorio. Pero no sólo opera sobre las cosas del mundo "objetivo" sino que también sobre el cuerpo de los peregrinos.

En la vida cotidiana los peregrinos lucen en sus cuerpos inscripciones de la virgen o del santo, usan objetos como camisetas, llaveros y otros soportes para manifestar su fe. En esta perspectiva, la religiosidad popular, rompe con la clásica distinción establecida por Durkheim (1992) en tanto existe una diferencia radical entre lo sagrado y lo profano. Si bien es cierto existe esa diferencia, en el mundo de los peregrinos es más tenue. En sus sedes sociales, en un altar, mantienen la imagen de la virgen que preside las reuniones, y en las casas se guarda respeto hacia ella.

Por otro lado, la religiosidad popular pone en escena narrativas nacionalistas como étnicas. A través de sus prácticas dejan en claro que son chilenos, pero que también portan una identidad regional mestiza y popular. Siguiendo la expresión de Chatterjee (2008), se trata de un espacio y de un tiempo, significado no de forma lineal, sino ritual. Por lo mismo hay un espacio sagrado, en este caso La Tirana o la quebrada de Tarapacá, llamada también como "la quebrada del amor".

Cuando decimos que reflexionamos desde las prácticas religiosas, afirmamos la idea de que, a través de la acción, observamos y analizamos un conjunto de prácticas religiosas que a más de un siglo, muestran una vitalidad y actualización de las mismas, que no deja de sorprender, desafiando las más clásicas de

4. Garrido, P. (dir.) (1944). La Tirana [Cineteca de la Universidad de Chile]. De http://cinetecavirtual.cl/cineteca/index.php/Detail/ objects $/ 2492$ 
las tesis de la secularización, esgrimidas tanto por desarrollistas de izquierda y de derecha (Van Kessel y Droogers, 1988). La religiosidad popular del Norte Grande de Chile, muestra signos más que evidente hacia una larga vida. La socialización que los padres hacen a sus hijos para continuar esta tradición, el ingreso de niños y niños a los bailes religiosos o bien a las bandas de músicos, nos señalan que esta tradición tiene mucho futuro ${ }^{5}$.

Mirar desde las prácticas religiosas implica enfatizar la dinamicidad, paradoja y contradicción de las mismas, además de lo azaroso, no reglamentado y lo contingente de las mismas (Maffesoli, 1997). En esta perspectiva nos ubicamos y situamos en el marco de un territorio, en este caso, el Norte Grande, con su historicidad, sus peculiaridades socioculturales, su relación con la nación y con los países al que perteneció: Perú y Bolivia.

\subsection{La fiesta: reforestar el desierto}

La fiesta de La Tirana es la única que se realiza en pleno desierto de Atacama. El ambiente hostil se soporta por que se va a adorar a la madre. La noción de sacrificio está presente. Hasta los años 50 del siglo pasado, por las noches, se encendían fogatas para alumbrarse y protegerse del frío. En el día el calor se hacía insoportable. Las cofradías religiosas bailaban tanto en el día como en la noche. Obreros y obreras de las oficinas salitreras dejaban de trabajar para asistir cada 16 de Julio, y con ello, además encontrarse con sus cercanos. La fiesta no sólo era el cumplir el ritual, sino que también, el lugar del encuentro. Nunca fue un lugar vacío.

Cuando Villalobos publicó el año 1979 su clásico libro La economía de un desierto... recoge la tradición de concebir al desierto como un lugar vacío. Cito del prólogo este párrafo:

Aislada entre las fuerzas de la naturaleza, la criatura humana ha sentido allí la presencia de espíritus animistas, la proximidad de los dioses o el acecho de los demonios. Palpó su dimensión insignificante en la cosmogonía, abrumadora por el dominio del sol o mientras observó el mansaje vacilante de las estrellas en el frío de la noche. Creyó adueñarse de la libertad, cuando solo se hacía más esclava, y sintió la belleza dramática del paisaje que muy pocos podían contemplar (Villalobos, 1979, p. 9).

El prólogo está lleno de una prosa que describe al desierto casi como un clisé. Pero en el fondo, obedece a una forma ilustrada de ver el paisaje. El desierto o mejor dicho los desiertos, en plural, siempre están asociados a economía subdesarrollada. Observando la bibliografía se nota la ausencia del clásico texto de Murra, editado en el año 1975, que significó otra forma de ver el espacio a través de la idea del desplazamiento de oriente a occidente, de norte a sur, y articulación de diversos nichos ecológicos. El desierto es un nicho más y tiene su función, quizás menor en términos económicos, pero no así en términos simbólicos. Piénsese por ejemplo en el uso del salitre, de los árboles y su uso como carbón, y por cierto en la riqueza de petroglifos y geoglifos. Pero además implica, al hacerse cargo, de lo planteado por Murra, la idea de desplazar la visión del paisaje, desde una mirada horizontal a una vertical. Los pastores bajando de la puna a las quebradas y luego a la costa y vice-versa.

Enfatizo el texto de Villalobos porque en su libro ya citado, estructura la economía del desierto en función de la minería. Y en este caso la de Huantajaya en el siglo XVI. Si seguimos avanzado en el tiempo hasta el siglo XIX será la minería del salitre la que pondrá al Norte Grande en el mapa del mundo. Y en la actualidad, lo es la minería en altura, en este caso, del cobre.

Hay un eje estructurante entre desierto y religiosidad popular que está marcado por la explotación minera. Es más, en el caso de San Lorenzo es definido como el santo de los mineros ${ }^{6}$. Terminada la actividad del salitre, La Tirana, ha ido cambiando en su fisonomía, aunque aún es posible hallar variadas manifestaciones de su desarrollo, cofradías religiosas que aún mantiene las denominaciones salitreras, como, por ejemplo, el

5. Sin embargo, hay bailes tradicionales como el Chino de Andacollo y las Cuyacas de Iquique que tienen problemas para reclutar bailarines jóvenes.

6. Se realiza cada 10 de agosto en la quebrada de Tarapacá. 
baile Moreno de la ex Oficina Salitrera Victoria (Guerrero \& Basaure, 2017), el de Humberstone, entre otros. Y nuevos bailes que se inspiran en los de Bolivia como los sambos caporales, morenadas, etc.

La fiesta colorida y musical del Norte Grande puede ser vista como un intento de dotar al desierto de lo que carece: flores, colores, plumas, sonidos, cantos y bailes que hablan de una domesticación parcial y temporal de ese paisaje, pero sin alterar su natural composición. Los bailes religiosos en el templo cantan. Son canciones breves que tiene una lógica: entrada, saludos y despedida. Su origen es colectivo y su transmisión opera, vía la existencia de pequeñas libretas, escrita a mano o ahora por ordenador. Sus textos analizados por Van Kessel (1970) hablan entra otras cosas de campos naturales, largo camino, pecados, todo ello enunciado por un nosotros: “Venimos de lejanas tierras". También está presente el tópico de la flor. Por ejemplo: "Aquí está la virgen pura/ preciosa más que un clavel/ que venimos adorarla/con la clara luz del día" (1970, p 153). Una oficina salitrera llevaba el nombre de "Flor de Chile". Como se advierte las referencias a la flora son evidentes.

Por lo mismo la fiesta es el lugar de la congregación, de la unión de la fraternidad. Es la instancia donde los vínculos comunitarios se actualizan y proyectan. Las coordenadas de tiempo y espacio de la vida cotidiana, del trabajo se suspenden, y se vive bajo la égida del tiempo y espacio sagrado.

El tiempo del alba, en el caso de la rompía del día, en la fiesta de San Lorenzo, cada 10 de agosto, en el pueblo de Tarapacá, así lo señala. La víspera en La Tirana, la noche que lleva del 15 al 16 de julio se marca como un hito especial. Momentos fuertes en la que la comunidad en conjunto, expresa su fe. No olvidemos la religiosidad popular es una fiesta de masas.

En ambas celebraciones, la plaza, el templo, la sede social, lo sagrado está presente, pero no al modo de la iglesia oficial, sino al estilo de la cultura popular, con cantos y danzas.

Luego de la fiesta, el desierto vuelve a su estado original. Sólo el sonido del viento suele escucharse, al igual que el paso de vehículos motorizados. Las sedes sociales de los bailes religiosos quedan cerradas, y en el año, cuando no es época de fiesta, se vuelve para mantener y cuidar sus pertenencias. Otros acuden a bautizar a sus hijos o hijas.

El paisaje en general y el desierto en particular, en estas condiciones puede ser visto como una especie de memoria histórica. Un lugar, en que los peregrinos antes del año 73, peregrinaban desde Iquique a La Tirana, recorriendo cerca de 74 kilómetros a pie. Se adentraban en el desierto, y de ese modo lo llegaban a conocer. Conocido era el camino de las Cruces que lo llevaban de Pozo Almonte al pueblo sagrado. Era como si los muertos "alumbraran los caminos"7. El desierto guardaba esas señas. El tendido de rieles y durmientes del ferrocarril era el camino que había que seguir. Los aventureros "cortaban" camino, como desafiando a esa inmensidad de arenas y de rocas. Ir a La Tirana, de generaciones en generaciones, genera un vínculo con el lugar.

Los términos: pampa, camanchaca, chuscas, china, caporales, chunchos, pieles rojas, gitanos, morenos o aquellas palabras que pertenecen al amplio diccionario de voces de la religiosidad popular mariana es familiarizar, llenar ese espacio visto desde afuera como vacío, por la mirada ilustrada.

El pueblo y sus alrededores, sus lugares, tienen una historia para los peregrinos. Muchos de ellos, han formado familias, se han casado, y su sueño es que sus niños o niñas, nazcan, en los días de fiestas. Los viejos, hombres y mujeres, desean morirse en tierra santa.

\section{DISCUSIÓN Y CONCLUSIONES}

Siguiendo la leyenda que da origen a la fiesta de La Tirana, y hasta antes de que el fraile Rondón encontrará la tumba con las cruces, esa parte del desierto de Atacama era de una sequedad absoluta. Un sitio donde no crecía nada y la vida no era posible.

El encuentro de las tumbas significó que la muerte daba vida. Esta vez a un largo y complejo peregrinaje. La falta de registros históricos impide saber acerca de su desarrollo hasta, por menos, la segunda mitad del siglo XIX.

7. De la canción “La vergüenza” de Silvio Rodríguez. 
Durante la primera explotación del salitre que va desde el 1850 hasta el 1930, año en que se produce la gran crisis económica mundial que significa una baja demanda por el salitre, el pueblo de La Tirana fue surtidora de agua y de leña. Pero, antes jugó un rol crucial en la explotación de la plata de Huantajaya ${ }^{8}$, un poblado que en el siglo XVI y XVIII se dinamizó por la minería.

Sobre las tumbas de la Ñusta Huillicac y Vasco de Almeyda se levantó una pequeña iglesia. De ese modo, el pueblo de La Tirana excedió su rol satelital a la industria de la plata y del salitre y empezó a poblarse. Uno de sus puntos claves fue la construcción de su capilla el año 1780 (Núñez, 1989) Esta fue devastada por un terremoto el año 1868. El actual templo fue construido en el 1866. Enfatizo estos datos ya que fue el inicio de un pueblo en vía de urbanización, que en la actualidad cuenta con una escuela básica, posta médica, cementerio, entre otros servicios.

La noción de lugares y de no lugares, sirve, para caracterizar espacios que, por influencias diversas, se transforman en otros. En el caso de la llamada sobremodernidad que analiza Augé (2000), la creación de los llamados no-lugares. Pero, aun así, un no lugar puede transformarse en un lugar debido, entre otras cosas, por ejemplo, a la frecuencia de los flujos que allí se establezcan. Un pasajero frecuente, de una u otra manera, puede desarrollar con personal del aeropuerto relaciones amicales. O bien un encuentro especial, amoroso, puede transformar ese no lugar en un sitio especial. "Ahí nos conocimos". La idea de las frecuencias de los contactos es importante para dotar a un no lugar en algo que tiene un aire especial. El 16 de julio en el pequeño pueblo la red de contactos se activa. Muchos peregrinos tienen su segunda casa, y durante el año acuden a mantener sus habitaciones, sobre todo en los meses de marzo a diciembre ya que, en enero, febrero y marzo, la playa se constituye en lugar de vacaciones.

Los lugares no son neutros y menos aún carecen de vida. La modernidad con su discurso filosófico y económico, declaró a la naturaleza como algo muerto, sin vida y con ello abrió el camino para la explotación irracional de los recursos (Berman, 1987). Para la mentalidad no racional, no ilustrado, como la de los peregrinos del Norte Grande, el desierto de Tarapacá, es un espacio no homogéneo. Tiene espacios sagrados y profanos. Espacios vacíos y espacios llenos de significación y de densidad mitológica. De hecho, en el habla cotidiana del Norte Grande no se usa la palabra desierto, se utiliza la noción de pampa. Su gentilicio pampino, denota arraigo y lealtad al territorio.

Las animitas, los cementerios esparcidos en todo el Norte Grande y, sobre todo los centros de peregrinajes expresan lo anterior de un modo explícito. Del mismo modo como están los restos de las más de 150 oficinas salitreras que funcionaron en los tiempos de la explotación del nitrato. La noción de pampa no es más que el desierto arraigado en la historia de sus habitantes. "Que la pampa nuenca muera" es la expresión usada por hombres y mujeres, que sintetiza la vinculación afectiva que mantienen con el desierto.

Este peregrinaje se sostiene sobre los bailes o cofradías religiosas. Organizaciones territoriales que desde las ciudades puertos del Norte Grande se preparan para saludar a la Madre. La creación de nuevos bailes religiosos, con sus vestimentas y danzas, es un proceso creativo que surge desde esos grupos y que inspiran muchas veces, en el cine y anteriormente en los comics como es el caso de los bailes pieles rojas o gitanos.

El espacio público de las ciudades de América latina cercenado por el modelo neoliberal, construye remedos de espacios públicos al que se concurre como consumidor y no como ciudadano. Aparecen los no-lugares, vacíos de sentidos. La religiosidad popular del Norte Grande sigue, sin embargo, en cada ciclo ritual, reproduciendo esta ocupación profunda del espacio, en este caso del desierto. La Tirana es un lugar que le pertenece, faltar a la fiesta es casi imperdonable. El año 2020 por el Covid 19, no se realizó el peregrinaje, pero en los barrios populares de las ciudades, se alzaron imágenes de la virgen, y se escucharon canciones alusivas a la festividad.

Cada uno de estos lugares es un jardín modelado y cuidado por las manos de los seres humanos que, convocados por su fe, al danzar y al bailar hacen como dice la canción del epígrafe "florecer el rosal".

8. Centro minero de explotación de plata, ubicado a 9 kms de la ciudad de Iquique y $70 \mathrm{kms}$ del pueblo de La Tirana. 


\section{Agradecimientos}

Al proyecto "Puesta en valor digital y formación del capital humano, para el Patrimonio Intangible de Tarapacá", financiado por el Gobierno Regional de Tarapacá y ejecutado por el Instituto de Estudios Andinos "Isluga" de la Universidad Arturo Prat, Iquique, Chile.

\section{Declaración responsable y conflicto de intereses}

El autor declara que no existe ningún conflicto de interés con relación a la publicación de este artículo.

\section{REFERENCIAS}

Advis, P. (2008). El Desierto conmovido. Paso de la hueste de Almagro por el norte de Chile. Universidad Arturo Prat.

Arriaza, B. (2015). Cultura Chinchorro. Las momias artificiales más antiguas del mundo. Editorial Universitaria (Santiago de Chile).

Augé, M. (2000). Los no lugares, espacios del anonimato. Una antropología de la sobremodernidad. Editorial Gedisa.

Augé, M. (2014). El antropólogo y el mundo global. Siglo veintiuno editores.

Bachelard, G (2012). La poética del espacio. Fondo de Cultura Económica

Bayo, J. (1995). Una flor en el desierto: Hermano Valero: sembrador del Evangelio.

Berman, M. (1987). El reencantamiento del mundo. Cuatro Vientos editorial.

Bhabha, H. (2002). El lugar de la cultura. Manantial.

Bravo, P. y Guerrero, B. (2000). Historia y ficción literaria sobre el ciclo salitrero en Chile. Ediciones Campus. Universidad Arturo Prat.

Durkheim, E. (1992). Las formas elementales de la vida religiosa. Ediciones Akal.

Chatterjee, P. (2008). La nación en tiempo heterogéneo y otros estudios subalternos. Siglo veintiuno editores, Clacso.

Giddens, A. (1995). La Constitución de la Sociedad. Bases para una Teoría de la Estructuración. Amorrortu Editores.

Guerrero B. \& Basaure, F. (2017). La Victoria de los Morenos. Universidad Arturo Prat y Gobierno Regional de Tarapacá.

Guerrero. B, (1994). A Dios rogando los pentecostales en la sociedad aymara del Norte Grande de Chile. Departament of Cultural Anthropology \& Sociology of Development. University Press

Guerrero, B. (2018). Religiosidad popular en el Norte Grande de Chile. Reflexiones sobre las prácticas religiosas. En Esquivel y Giménez (eds.) Religiones en cuestión. Campos, fracturas y perspectivas (pp. 401-418). ACSRM

Guerrero, B. (2017). "La reina del Tamarugal": Las dimensiones locales del culto mariano de La Tirana. Paisajes y espacios sonoros. Revista de Ciencias Sociales (CI), 39, pp. 8-26. https://www.redalyc.org/pdf/708/70854366001.pdf

Gutiérrez, H. (1956). Crónica de un soldado de la guerra del Pacífico. Editorial del Pacífico S.A.

Lalive, C. (1968). El Refugio de las Masas. Editorial del Pacíficio

Maffesoli, M. (1997). Elogio de la razón sensible. Una visión intuitiva del mundo contemporáneo. Paidós, Studio.

Martín, E. (2007). Aportes al concepto de religiosidad popular: una revisión de la bibliografía argentina. En M.J. Carozzi \& C. Ceriani Cernadas (coord.) Ciencias Sociales y religión en América Latina (pp. 61-86). Editorial Biblios.

Murra, J. (1975). Formaciones económicas y políticas del mundo andino. Instituto de Estudios Peruanos.

Núñez, L. (1989). La Tirana, del misterio al sacramento. Departamento de Teología. Universidad del Norte.

Núñez A. (2015). La construcción social del mito de La Tirana. Mensaje, 64 (640), 40.

Parvex, G. (2017). Un veterano de tres guerras. Recuerdos de José Miguel Varela. Academia de Historia Militar.

Plath, O. (2012) La animita. Fondo de Cultura Económica.

Segato, R. (2007) La Nación y sus Otros. Raza, etnicidad y diversidad religiosa en tiempos de Políticas de Identidad. Prometeo.

Tennekes, H. \& Koster, P. (1986). Iglesia y Peregrinos en el Norte de Chile: Reajustes en el Balance de Poderes. Cuaderno de Investigación Social, 18, 57-86. Centro de Investigación de la Realidad del Norte, Iquique, Chile. 
Van Kessel, J. \& Droogers, A. (1988). Secular views and sacred vision: sociology of development and the significance of religion in Latin America. En P. Quarles Van Ufford y M. Schoffeleers (eds.). Religion and Development. Towards an integrated approach (pp. 53-72). Free University Press Amsterdam.

Van Kessel, J. (1970). El desierto canta a María. Bailes Chinos de los Santuarios Marianos del Norte Grande. Serie: La fe de un Pueblo. Tomo II. Ediciones Mundo.

Van Kessel, J. (1987). Lucero del desierto, mística popular y movimiento social. Universidad Libre de Amsterdam. Centro de Investigación de la Realidad del Norte, Iquique.

Vicuña, M. (1995). La imagen del desierto de Atacama (XVI-XIX). Del espacio de la disuasión al territorio de los desafíos. Editorial Universidad de Santiago.

Villalobos, S. (1979). La economía de un desierto. Tarapacá durante la Colonia. Ediciones Nueva Universidad. 